Revista Destaques Acadêmicos, Lajeado, v. 10, n. 4, 2018. ISSN 2176-3070

DOI: http://dx.doi.org/10.22410/issn.2176-3070.v10i4a2018.2041

http://www.univates.br/revistas

\title{
AVALIAÇÃO DOS TEORES DE ÁCIDOS GRAXOS PRESENTES EM AZEITES DE OLIVA EXTRA VIRGEM COMERCIALIZADOS NO VALE DO TAQUARI
}

\author{
Rosemeri Scherer ${ }^{1}$, Wolmir José Böckel ${ }^{2}$
}

Resumo: O consumo de alimentos saudáveis tem aumentado nos últimos anos. Os consumidores estão, cada vez mais, buscando alimentos mais seguros e com maior qualidade nutricional. $\mathrm{O}$ azeite de oliva extra virgem apresenta-se entre estes alimentos. Ele destaca-se por ser extraído mecanicamente e sem o uso de solventes e também por possuir ácidos graxos em sua composição, que auxiliam na redução do colesterol. Cuidados a partir do cultivo, coleta e produção de azeite são muito importantes para obtenção de um azeite de boa qualidade. Como consequência, as tentativas de adulteração deste produto com outros tipos de óleos ou azeites mais baratos como, por exemplo, o azeite de oliva refinado e o óleo de soja, são comuns, tendo em vista que a produção é pequena. Os objetivos deste trabalho foram a determinação quantitativa dos teores de ácidos graxos e seus valores comparados com a legislação brasileira vigente, bem como averiguar se os azeites de oliva extra virgem sofreram algum tipo de adulteração com adição de óleos ou azeites mais baratos. Foram analisadas 4 amostras de diferentes marcas de azeites de oliva extra virgem, adquiridas em supermercados na região do vale do Taquari, de acordo com os métodos oficiais descritos em Zenebon, Pascuet e Tiglea (2008). Para todas as marcas avaliadas, o índice de acidez encontra-se dentro do padrão estabelecido pela legislação (BRASIL, 2012). Isto indica que os frutos, utilizados para a obtenção destes azeites, estavam no ponto ótimo de maturação onde também o processamento e armazenamento foram adequados.

Palavras-chave: Azeite de Oliva Extra Virgem. Ácidos Graxos. Adulteração.

\section{INTRODUÇÃO}

Entre os óleos vegetais comestíveis vendidos mundialmente, o azeite de oliva é um dos mais importantes e mais utilizados. Atualmente o azeite

1 Engenheira de Alimentos, Centro de Ciências Exatas e Tecnológicas/Laboratório de Química, Universidade do Vale do Taquari - Univates.

2 Docente do Centro de Ciências Exatas e Tecnológicas/Laboratório de Química, Universidade do Vale do Taquari - Univates. 
de oliva extra virgem representa oitenta por cento do volume desse mercado, enquanto os outros vinte por cento são do azeite de oliva tipo puro. De acordo com a Associação Brasileira de Produtores, Importadores e Comerciantes de Azeite de Oliveira - OLIVA, a tendência de crescimento aponta para um mercado quase cem por cento de produto extra virgem para os próximos anos (INMETRO, 2015). A expansão do comércio do azeite de oliva é acompanhada de sucessivos descobrimentos dos seus benefícios à saúde. Os ácidos graxos presentes no azeite de oliva são recomendados para o consumo humano, pois estão envolvidos com a diminuição dos níveis de colesterol ruim (LDL) do sangue devido à predominância dos ácidos graxos monoinsaturados, à presença das vitaminas $\mathrm{A}$ e $\mathrm{E}$, e aos antioxidantes, benéficos à saúde humana (INMETRO, 2015; PINHEIRO et al., 2005).

O azeite de oliva é o único no setor de óleos e gorduras que possui seu próprio acordo internacional de comércio, o Conselho Oleícola Internacional (COI), que coordena a produção, garantindo qualidade e autenticidade (ALVES, 2010). Para obtenção de sua alta qualidade, deve ser obtido através do processamento de azeitonas sadias, frescas, colhidas no período ideal da maturação, sendo extraídas mediante pressão física, sem uso de solventes, obtendo-se assim melhor qualidade nos caracteres organolépticos e na avaliação físico química (CARDOSO, 2006).

As características de qualidade de um óleo ou azeite que contém lipídeos estão relacionadas com o fenômeno da rancidez, ou seja, a deterioração deste tipo de produto. Existem dois tipos de rancidez, a hidrolítica e a oxidativa (MORETTO; FETT, 1998). A rancidez hidrolítica enzimática refere-se à hidrólise das gorduras e óleos, onde há produção de ácidos graxos livres, devido à ação das enzimas lipases presentes nas oleaginosas ou lipases de origem microbiana. As de origem animal preferem meios ligeiramente alcalinos e as de origem vegetal meios ligeiramente ácidos. Também pode ocorrer a forma não enzimática, ou seja, pode ocorrer durante os processos de fritura, nos quais a hidrólise se dá a altas temperaturas, produzindo ácidos graxos livres (MORETTO; FETT, 1998). A rancidez oxidativa está relacionada com ácidos graxos insaturados. Acontece reação do oxigênio atmosférico com as duplas ligações dos ácidos graxos insaturados. Quanto maior o número de insaturações maior a reatividade. A reação de oxidação produz peróxidos que dão odor de ranço ao alimento (MORETTO; FETT, 1998).

Na tecnologia de alimentos, a reação mais importante de oxidação de ácidos e gorduras insaturadas é a oxidação pelo oxigênio do ar ou autoxidação. Esta reação se dá por um mecanismo de radicais livres e é caracterizada pelo aparecimento de um cheiro desagradável do alimento, que vai se tornando cada vez mais forte até atingir o característico odor de ranço. Esse causado por aldeídos e ácidos de baixo peso molecular oriundos na decomposição do produto. Quanto mais insaturado for o ácido graxo ou a gordura do produto, mais facilmente sofrerá rancificação (BOBBIO, 2003). 
Os peróxidos são produtos formados a partir da oxidação de óleos e gorduras devido à ação do oxigênio. $\mathrm{O}$ índice de peróxido é um dos métodos mais usados para medir o estado de oxidação dos óleos e gorduras. Devido à sua ação oxidante, os peróxidos orgânicos atuam sobre o iodeto de potássio, proporcionando a medida do conteúdo de oxigênio reativo, liberando iodo que será titulado com tiossulfato de sódio, usando como indicador o amido. $\mathrm{O}$ índice de peróxido é expresso em miliequivalentes de oxigênio ativo por quilograma de azeite (MORETTO; FETT, 1998; CECCHI, 2003). O limite do índice de peróxido para que o azeite de oliva seja considerado próprio para o consumo humano estabelecido em Brasil (2012) é de no máximo de $20 \mathrm{mEq} \cdot \mathrm{kg}^{-1}$.

A cor é um componente sensorial importante na apresentação de um azeite extra virgem, está relacionada principalmente com a presença de clorofila e feofitina. Os carotenoides presentes contribuem também para a cor e protegem o azeite da fotoxidação, ou seja, protege os ácidos graxos insaturados do azeite, do processo oxidativo, resultante da exposição à luz, fotossensores (clorofila) e oxigênio (PENZ, 2010; ARAÚJO, 2009). A presença de clorofila é indicada pela cor esverdeada dos azeites de oliva, a cor verde indica que a estrutura da clorofila inicial foi mantida, ou seja, o azeite não passou por processos de aquecimento na extração (ARAÚJO, 2008).

A determinação dos coeficientes de absorção no espectro ultravioleta (UV) a 232nm e 270nm (extinção específica), usados para estimar o estado de oxidação na fração insaponificável dos azeites, também são empregadas para verificar a presença de óleos refinados no azeite de oliva virgem. Compostos de oxidação dos dienos conjugados contribuem para K232 (nível de oxidação) enquanto compostos de oxidação secundária (aldeídos, cetonas, etc.) contribuem para K270 (se houve processamento e ou refino). Estes últimos são formados, a partir de ácidos graxos insaturados como linoleico (C18:2). Valores acima das faixas de absorção de UV podem indicar a presença de óleos oxidados, de má qualidade, possível refinação e ou adulteração com óleos refinados de oliva ou de óleos de sementes (YILDIRIM, 2009). Os limites estabelecidos em Brasil (2012) são para o K232 $\leq 2,5$ e para $K 270 \leq 0,22$.

Outro dado importante da avaliação do estado de conservação do óleo é a determinação da acidez, pois a decomposição, seja por hidrólise ou oxidação, altera quase sempre a concentração dos íons hidrogênio, sendo acelerada pelo aquecimento e a luz. Ácidos graxos livres são formados pela rancidez. Estes são frequentemente expressos em termos de índice de acidez, ou em massa percentual do componente ácido principal, geralmente o ácido oleico. $\mathrm{O}$ índice de acidez segundo é definido como o número de miligramas de hidróxido de potássio necessário para neutralizar um grama de ácidos graxos livres na amostra. Os métodos que avaliam a acidez titulável resumemse em titulações alcalimétricas com auxílio de indicador de mudança de cor (ZENEBON; PASCUET; TIGLEA, 2008; MORETTO; FETT, 1998). Pelo fato de o azeite de oliva conter mais de $80 \%$ de ácidos graxos insaturados, sendo 
o ácido oleico o principal (MORETTO; FETT, 1998), o índice de acidez livre, expressa em percentual de ácido oleico, pode ser classificado em extra virgem, virgem e lampante, com os índices de acidez livre máximos de 0,8 \% e 2,0 \%, respectivamente, e maior que 2,0 \% para o lampante. BRASIL, (2012)

O perfil de ácidos graxos é utilizado como padrão de identidade e qualidade, pois, assim como para outros óleos, segue um padrão específico para o azeite de oliva, o qual pode apresentar alterações, segundo o grau de decomposição oxidativa (COI, 2009). A autenticidade dos óleos vegetais tendo em vista a expansão do mercado tornou-se um assunto importante, de amplo interesse comercial e, ainda, do ponto de vista da saúde. A diferença entre o preço de um azeite de oliva e um óleo comestível, por exemplo, pode ser um meio das indústrias auferirem ganhos, através da adição de óleos mais baratos aos azeites de oliva extra virgem. Dessa forma, infere em prejuízos para os consumidores de azeite de oliva, pois acreditam fazer a aquisição de um produto benéfico à saúde e na verdade, parte deste produto pode não ser originário da azeitona (MODOLO, 2007). A composição em ácidos graxos é como a identidade do óleo. Cada óleo tem uma composição característica. A principal característica do azeite de oliva é sua composição em ácido oleico e isso deve ser demonstrado no ensaio de determinação em ácidos graxos (INMETRO, 2015). A composição em ácidos graxos pode ser empregada como um dos parâmetros em estudos de verificação de adulteração, pois cada um dos óleos vegetais possui uma diferente característica. Ácidos graxos podem ser determinados e analisados a partir dos ésteres metílicos, auxiliando no estudo de fraudes e na avaliação nutricional de óleos e de gorduras de origem vegetal ou animal. A cromatografia gasosa é o método utilizado para determinação dos ácidos graxos. (ZENEBON; PASCUET; TIGLEA, 2008; COLLINS; BONATO, 2005; LANÇAS, 1993).

Este trabalho traz a avaliação de alguns parâmetros físico-químicos de quatro marcas de azeite de oliva extra virgem comercializados na região do Vale do Taquari, Rio grande do Sul, tais como: índice de acidez e de peróxido, cor, coeficiente de extinção específica $\mathrm{K}_{232}, \mathrm{~K}_{270}$ e os teores de ácidos graxos. Os resultados foram comparados com a legislação brasileira vigente Brasil (2012) e avaliados quanto à possibilidade de adulteração com óleos vegetais de menor preço de mercado.

\section{METODOLOGIA}

As amostras de azeite de oliva extra virgem foram coletadas no varejo da região do Vale do Taquari, Rio Grande do Sul, e denominadas como A, B, C e D. Sendo, produzidas e envasadas, respectivamente, na Espanha, Argentina, Brasil e Portugal. Todas estavam dentro do prazo de validade. Foram determinados os índices de acidez e peróxido, coeficiente de extinção específica no UV e o teor em ácidos graxos. A metodologias das análises são descritas a seguir. 


\section{Índice de Acidez}

Para o preparo das amostras foram utilizados $2 \mathrm{~g}$ dissolvidos em 25 $\mathrm{ml}$ de solução de éter-álcool (2:1) neutra, $\mathrm{pH}$ 7,0 \pm 0,10 e titulado com solução padrão de hidróxido de sódio 0,1 mol. $^{-1}$ com indicador fenolftaleína. (BRASIL, 2005; ZENEBON; PASCUET; TIGLEA, 2008 ). O índice de acidez em ácido oleico (AAO) foi obtido pela Equação 1 (Zenebon; Pascuet; Tiglea, 2008):

$$
\% \mathrm{AAO}=\frac{V \times f \times 0,0282 \times 100}{P}
$$

Onde, $\mathrm{V}=$ volume de hidróxido de sódio $0,1 \mathrm{M}$ gasto na titulação, $\mathrm{f}=$ fator da solução de hidróxido de sódio $0,1 \mathrm{~mol}^{-\mathrm{L}^{-1}}, \mathrm{P}=$ massa da amostra em gramas da alíquota e 0,0282 = fator de conversão do ácido oleico (decimilésima parte da massa molar do ácido oleico).

\section{Índice de Peróxido}

Em alíquotas de $5 \mathrm{~g}$ das amostras foram adicionados $30 \mathrm{~mL}$ da solução de ácido acético-clorofórmio (3:2) e agitou-se até a dissolução da amostra. Adicionou-se $0,5 \mathrm{~mL}$ da solução saturada de iodeto de potássio e deixouse em repouso ao abrigo da luz por exatamente um minuto. Acrescentou-se $30 \mathrm{~mL}$ de água deionizada e $0,5 \mathrm{~mL}$ de solução de amido indicadora e não ocorreu aparecimento da coloração azul (as amostras não continham peróxido). Preparou-se uma prova em branco, nas mesmas condições (BRASIL, 2005; ZENEBON; PASCUET; TIGLEA, 2008). Para calcular o índice de peróxido (IP), em mEq kg-1 , utilizou-se a Equação 2 (ZENEBON; PASCUET; TIGLEA, 2008):

$$
\mathrm{IP}=\frac{(\mathrm{Va}-\mathrm{Vb}) \times \mathrm{N} \times 1000}{P}
$$

Onde, $\mathrm{Va}=$ volume da solução tiossulfato de sódio $0,01 \mathrm{~N}$ gasto na titulação; $\mathrm{Vb}=$ volume da solução tiossulfato de sódio $0,01 \mathrm{~N}$ gasto na titulação do branco; $\mathrm{N}$ = concentração molar da solução tiossulfato de sódio $0,01 \mathrm{~N}$ e $\mathrm{P}=$ massa da amostra em gramas da alíquota.

A cor dos azeites de oliva extra virgem foi determinada com o auxílio do espectrofotômetro Minolta CM-5. As coordenadas medidas foram L* (luminosidade), $\mathrm{a}^{*}$ (tonalidade de verde a vermelho), $\mathrm{e} \mathrm{b}^{*}$ (tonalidade de azul a amarelo).

\section{Coeficiente de Extinção Específica $\mathbf{K}_{232}, K_{270}$}

Pesou-se $250 \mathrm{mg}$ de cada amostra em um balão volumétrico de $25 \mathrm{~mL}$ e avolumou-se com ciclo-hexano. Homogeneizou-se com auxílio de agitador 
de tubos (vortex) por 30 segundos. Preparou-se uma prova em branco (ciclohexano puro) nas mesmas condições. As leituras forma realizadas em cubetas de quartzo por espectrometria nos comprimentos de onda em 232nm e $270 \mathrm{~nm}$ (YILDIRIM, 2009). Os resultados K232 e K270 são expressos de acordo com a equação 3 (European Union Commission, 1991):

$$
K_{\lambda}=\frac{E_{\lambda}}{c \times s}
$$

Onde, $K_{\lambda}=$ extinção específica no comprimento de onda $\lambda ; \mathrm{c}=$ concentração da solução em gramas por $100 \mathrm{~mL}$; s = espessura da cubeta de quartzo; $E_{\lambda}=$ extinção medida no comprimento de onda $\lambda$.

\section{Determinação dos teores em ácidos graxos}

As análises de ácidos graxos foram realizadas no laboratório de Ciência e Qualidade de Alimentos, no estado de São Paulo. O azeite de oliva foi caracterizado conforme metodologias oficiais da AOAC, (2014) e ISSO (2014). Para a determinação do perfil de ácidos graxos do azeite de oliva por cromatografia gasosa, a amostra de óleo foi extraída com solventes orgânicos e derivatizada com $\mathrm{BF}_{3}$ a $7 \%$ e $1 \mathrm{~mL}$ de tolueno. Selaram-se os frascos com septo de teflon e aqueceu-se a $105^{\circ} \mathrm{C}$ em estufa por 45 minutos (agitaram-se a cada 10 minutos). Após resfriamento da amostra a temperatura ambiente, foram adicionados à mistura derivatizada $5 \mathrm{~mL}$ de água destilada e $1 \mathrm{~mL}$ de n-hexano. As fases orgânica e aquosa foram separadas, na fase orgânica contendo os ésteres graxos foi adicionado cerca de $1 \mathrm{~g}$ de sulfato de sódio anidro e agitou-se. Injetou-se $1 \mu \mathrm{L}$ da fase orgânica no cromatógrafo a gás (amostra e do padrão). Os componentes foram separados em coluna capilar de sílica fundida SP2560, de $100 \mathrm{~m}$, com diâmetro interno de $0,25 \mathrm{~cm}$ e espessura do filme de 0,20 $\mu \mathrm{m}$. Foram obedecidas as seguintes condições temperatura do injetor: $220{ }^{\circ} \mathrm{C}$; temperatura do detector FID: $220{ }^{\circ} \mathrm{C}$; gás de arraste: hidrogênio. Os ácidos graxos foram identificados através da comparação dos tempos de retenção dos padrões de ésteres metílicos de ácidos graxos e das amostras e a quantificação foi feita por normalização de área.

\section{RESULTADOS E DISCUSSÃO}

Para todas as marcas avaliadas, o índice de acidez encontra-se dentro do padrão estabelecido pela legislação (BRASIL, 2012). Isto indica que os frutos, utilizados para a obtenção destes azeites, estavam no ponto ótimo de maturação onde também o processamento e armazenamento foram adequados. Os valores obtidos experimentalmente, conforme Tabela 1, estão de acordo com o declarado no rótulo dos lotes avaliados. Já na análise de índice de peróxido, os resultados foram negativos para todas as amostras A, B, C e D. Isto representa 
que os azeites avaliados estão dentro do limite estabelecido por BRASIL (2012) que é de no máximo de $20 \mathrm{mEq} \cdot \mathrm{kg}^{-1}$. Segundo Caldas et al. (2012) o azeite de oliva extra virgem possui em sua composição potentes antioxidantes como o - tocoferol, a clorofila e os compostos fenólicos, que agem em condições adequadas (ausência de luz) como sequestradores de radicais livres. A clorofila nos óleos, no processo de auto-oxidação, pode ser um sensibilizador do oxigênio, e na presença de luz, atua como pró-oxidante, e na ausência de luz atua como antioxidante. Os tocoferóis (vitamina E) possuem atividade antioxidante natural. $\mathrm{O}$ azeite de oliva pode também conter quantidades variáveis de substâncias fenólicas, potentes antioxidantes que apresentam importante papel na estabilidade oxidativa dos azeites, pois adiam a oxidação.

Quanto ao coeficiente de extinção específica no ultravioleta (K232 e K270), todas as amostras tiveram resultados dentro do limite estabelecido por Brasil (2012), conforme Tabela 1. Quanto à marca B, o resultado demostra que o estado de oxidação na fração saponificável no K232 está próximo do máximo estabelecido em Brasil (2012). Nesse sentido, tendo em vista que a embalagem desta marca é frasco plástico de coloração verde, possivelmente pode estar ocorrendo fotooxidação. Conforme descrito em Oetterer (2006) à fotooxidação é maior em embalagens plásticas do que nas embalagens feitas de vidro.

Tabela 1 - Resultado obtidos para o índice de acidez em percentual de ácido oleico e os coeficientes de extinção específica no ultravioleta (K232 e K270) das amostras de azeite de oliva extra virgem.

\begin{tabular}{c|c|c|c}
\hline Marcas & $\begin{array}{c}\text { Acidez (\% de ácido } \\
\text { oléico) } \pm \text { D.P. }\end{array}$ & $\mathbf{K}_{232} \pm$ D.P. & $\mathbf{K}_{270} \pm$ D.P. \\
\hline A & $0,04 \pm 0,01$ & $1,81 \pm 0,07$ & $0,11 \pm 0,01$ \\
\hline B & $0,06 \pm 0,01$ & $2,42 \pm 0,06$ & $0,11 \pm 0,00$ \\
\hline C & $0,04 \pm 0,00$ & $2,15 \pm 0,01$ & $0,10 \pm 0,01$ \\
\hline D & $0,03 \pm 0,00$ & $2,01 \pm 0,01$ & $0,09 \pm 0,01$ \\
\hline
\end{tabular}

Fonte: os autores.

Todas as amostras avaliadas neste trabalho apresentaram no K270 valores que indicam que as amostras não sofreram processo de refino e ou adulteração com óleos refinados ou de óleos de sementes, conforme descrito por Yildirim (2009).

A cor foi verificada na abertura das amostras sem exposição à luz. Na Tabela 2 é possível verificar a variação da cor das amostras analisadas. A partir do diagrama de Minolta, pode observar as coordenadas de cor no espaço de cor $\mathrm{L}^{*} \mathrm{a}^{*} \mathrm{~b}^{*}$. As diferenças de cor são definidas pala comparação da cor entre as quatro marcas avaliadas. $\mathrm{O} \Delta \mathrm{L}^{*}$ representa a diferença do claro $\left(+\mathrm{L}^{*}\right)$ para o 
escuro (- $\left.\mathrm{L}^{*}\right), \mathrm{o} \Delta \mathrm{a}^{*}$ representa a diferença do vermelho $\left(+\mathrm{a}^{*}\right)$ para o verde $\left(-\mathrm{a}^{*}\right)$, e $\mathrm{o} \Delta \mathrm{b}^{*}$ representa a diferença do amarelo $\left(+\mathrm{b}^{*}\right)$ para o azul $\left(-\mathrm{b}^{*}\right)$.

Tabela 2 - Parâmetro de cor das amostras de azeite de oliva extra virgem nas coordenadas $\mathrm{L}^{*}, \mathrm{a}^{*} \mathrm{e} \mathrm{b}^{*}$.

\begin{tabular}{c|c|c|c}
\hline \multirow{2}{*}{ Marcas } & \multicolumn{3}{|c}{ Coordenadas \pm D.P. } \\
\cline { 2 - 4 } & $\mathbf{L}^{*}$ & $\mathbf{a}^{*}$ & $\mathbf{b}^{*}$ \\
\hline A & $4,17 \pm 0,16$ & $0,39 \pm 0,04$ & $5,45 \pm 0,25$ \\
\hline B & $7,01 \pm 0,10$ & $-0,16 \pm 0,04$ & $1,38 \pm 0,16$ \\
\hline C & $6,98 \pm 0,15$ & $-0,01 \pm 0,04$ & $2,71 \pm 0,08$ \\
\hline D & $5,25 \pm 0,09$ & $0,23 \pm 0,07$ & $4,28 \pm 0,05$ \\
\hline
\end{tabular}

D.P.: desvio padrão.

Fonte: os autores.

Os resultados obtidos indicam pequena variação com tendência ao escurecimento da amostra. Verificou-se que as amostras B e C possuem cores mais próximas, ou seja, possuem uma intensidade maior da coloração verde e menor da coloração amarela. As amostras A e D possuem menor intensidade na coloração verde e a coloração amarela mais intensa. Essa coloração está relacionada principalmente com à presença de clorofila e feofitina, segundo Araújo (2008), a coloração verde indica que a clorofila se mantém no estado inicial, não passou por processo de aquecimento. Azeites ou oleos armazenados à luz, normalmente apresentam o $L^{*}$ maior, enquanto as armazenadas no escuro permanecem estáveis durante o período de armazenagem. $\mathrm{O}$ coeficiente de amarelecimento $\left(b^{*}\right)$ das amostras expostas à luz diminui significativamente, enquanto que daqueles armazenadas no escuro permanece constante durante todo o período de armazenagem. As alterações de cor estão relacionadas com a decomposição de clorofila no processo de fotoxidação (AYTON; MAILER; GRAHAM, 2012).

A composição em ácidos graxos das amostras analisadas, descritas na Tabela 3, são características do azeite de oliva extra virgem não adulterado, pois o teor e ácido oleico apresenta-se em maior concentração, enquanto que o teor em ácido linoleico apresentam-se em menor concentração, característico do azeite de oliva. Considerando Brasil (2012), as concentrações de ácidos graxos dos lotes avaliados estão de acordo. 
Tabela 3 - Composição em ácidos graxos determinado nas amostras das marcas A, B, C e D de azeite de oliva extra virgem.

\begin{tabular}{c|c|c|c|c}
\hline \multirow{2}{*}{ Ácidos graxos (AG) } & \multicolumn{4}{|c}{ Teor em AG (g 100 g-1 \pm D.P.) } \\
\cline { 2 - 5 } & $\mathbf{A}$ & $\mathbf{B}$ & $\mathbf{C}$ & $\mathbf{D}$ \\
\hline C 14:0 - mirístico & $\mathrm{Nd}$ & $\mathrm{Nd}$ & $\mathrm{Nd}$ & $\mathrm{Nd}$ \\
\hline C 16:0 - palmítico & $10,24 \pm 0,24$ & $14,61 \pm 0,38$ & $15,46 \pm 0,07$ & $12,24 \pm 0,22$ \\
\hline $\begin{array}{c}\text { C 16:1 - palmitoleico } \\
\text { (ômega 7) }\end{array}$ & $0,79 \pm 0,11$ & $1,53 \pm 0,03$ & $1,85 \pm 0,07$ & $1,15 \pm 0,11$ \\
\hline C 17:0 - margárico & $\mathrm{Nd}$ & $0,08 \pm 0,03$ & $\mathrm{Nd}$ & $0,08 \pm 0,05$ \\
\hline C 17:1 - cis-10-heptadecanoico & $0,10 \pm 0,00$ & $0,13 \pm 0,02$ & $0,19 \pm 0,05$ & $0,12 \pm 0,03$ \\
\hline C 18:0 - esteárico & $3,66 \pm 0,06$ & $2,27 \pm 0,04$ & $1,75 \pm 0,05$ & $2,85 \pm 0,10$ \\
\hline C 18:1 - oleico (ômega 9) & $72,80 \pm 0,80$ & $63,45 \pm 0,31$ & $65,12 \pm 0,15$ & $68,87 \pm 0,63$ \\
\hline C 18:2 - linoleico (ômega 6) & $5,60 \pm 0,20$ & $11,47 \pm 0,33$ & $9,61 \pm 0,23$ & $8,34 \pm 0,05$ \\
\hline C 18:3 - alfa linolênico (ômega & $0,37 \pm 0,07$ & $0,37 \pm 0,07$ & $0,36 \pm 0,06$ & $0,37 \pm 0,07$ \\
\hline 3) & $0,61 \pm 0,12$ & $0,61 \pm 0,12$ & $0,68 \pm 0,05$ & $0,59 \pm 0,08$ \\
\hline C 20:0 - araquídico & $0,20 \pm 0,04$ & $0,22 \pm 0,03$ & $0,27 \pm 0,08$ & $0,22 \pm 0,04$ \\
\hline C 20:1 - cis-11-eicosenoico \\
(ômega 11)
\end{tabular}

Nd: não detectado

D.P.: desvio padrão

Fonte: elaborada pela autora a partir dos resultados.

Conforme descrito por Lardini (2012), quando o azeite de oliva é adicionado e ou fraudado com óleo de qualidade inferior e ou de sementes, os valores de ácido linoleico tendem a aumentar.

Os resultados de ácido oleico e ácido linoleico mostraram que os percentuais obtidos em maior quantidade nos azeites de oliva extra virgem avaliados, variam de acordo com a variedade usada para elaborar o azeite, conforme mostrado no estudo Embrapa (2012) em que o percentual de ácido linoleico da variedade Manzanilla apresentou um conteúdo de 11,43\% e o ácido oleico em $63,60 \%$, e na variedade Grappolo tem-se 6,50\% de ácido linoleico e $77,55 \%$ de ácido oleico.

Segundo o CODEX (2003), ácidos graxos presentes no azeite de oliva extra virgem são: ácido oleico $(55,00$ a 83,00\% )(C18:1), ácido linoleico (3,50 a $21,00 \%)(\mathrm{C} 18: 2)$, ácido palmítico (7,50 a 20,0 \%) (C16:0), ácido palmitoleico (0,30 a 3,50\%) (C16:1) e ácido esteárico (0,50 a 5,00\%) (C18:0). Outros ácidos graxos, como o ácido $\alpha$-linolênico $(\leq 1,00 \%)(\mathrm{C} 18: 3)$, normalmente estão presentes na 
constituição do azeite de oliva, mas em quantidades inferiores a 1\%. BRASIL (2012).

Os valores de ácidos graxos saturados e insaturados (monoinsaturados, poli-insaturados), ômega 3, ômega 6 estão descritos na Tabela 4.

Tabela 4 - Resultados da determinação dos ácidos graxos saturados e insaturados.

\begin{tabular}{c|c|c|c|c}
\hline \multirow{2}{*}{$\begin{array}{c}\text { Tipos de ácidos } \\
\text { graxos (AG) }\end{array}$} & A & B & C & D \\
\cline { 2 - 5 } & $14,37 \pm 0,10$ & $17,49 \pm 0,15$ & $17,57 \pm 0,10$ & $15,70 \pm 0,14$ \\
\hline Saturados & $73,89 \pm 0,36$ & $65,33 \pm 0,33$ & $67,43 \pm 0,42$ & $70,16 \pm 0,36$ \\
\hline Monoinsaturados & $6,21 \pm 0,20$ & $12,08 \pm 0,24$ & $10,29 \pm 0,15$ & $8,93 \pm 0,18$ \\
\hline Poli-insaturados & $0,61 \pm 0,02$ & $0,61 \pm 0,02$ & $0,68 \pm 0,04$ & $0,59 \pm 0,04$ \\
\hline Ômega - 3 & $5,60 \pm 0,24$ & $11,47 \pm 0,24$ & $9,61 \pm 0,24$ & $8,34 \pm 0,10$ \\
\hline Ômega - 6 & & & &
\end{tabular}

D.P.: desvio padrão

Fonte: os autores.

Os teores em ácidos graxos denotam que os azeites são compostos na maior parte por ácidos graxos insaturados, por isso, solúveis a temperatura ambiente, conforme descrito no estudo de Pinheiro et al. (2005). Além disso, os resultados da composição em ácidos graxos mostraram que, os azeites avaliados não sofreram adulteração, pois apresentam composição característica, ou seja, o ácido oleico está presente em maior quantidade, conforme descrito também em Inmetro (2015).

Segundo Lardini (2012), Tabela 5, a amostra 1 (mistura de azeite de oliva virgem e óleo de soja) tem uma concentração de ácido graxo saturado maior, maior concentração de ácido linoleico (característico do óleo de soja) e menor concentração de ácido oleico, confirmando que a amostra é uma mistura de óleo de soja e azeite de oliva.

Tabela 5 - Resultados de ácidos graxos obtidos em estudo realizado em diferentes tipos de azeites de oliva

\begin{tabular}{c|c|c|c|c}
\hline Amostra & $\begin{array}{c}\text { C:16:0 ácido } \\
\text { palmítico }\end{array}$ & $\begin{array}{c}\text { C:18:1 ácido } \\
\text { oléico }\end{array}$ & $\begin{array}{c}\text { C:18:2 ácido } \\
\text { linoléico }\end{array}$ & $\begin{array}{c}\text { C: 18:3 alfa- } \\
\text { ácido linolénico }\end{array}$ \\
\hline 1 & $11,65 \%$ & $30,09 \%$ & $47,74 \%$ & $5,64 \%$ \\
\hline 2 & $10,27 \%$ & $78,59 \%$ & $5,81 \%$ & $0,57 \%$ \\
\hline 3 & $15,56 \%$ & $66,69 \%$ & $13,22 \%$ & $0,72 \%$ \\
\hline
\end{tabular}




\begin{tabular}{c|c|c|c|c}
\hline Amostra & $\begin{array}{c}\text { C:16:0 ácido } \\
\text { palmítico }\end{array}$ & $\begin{array}{c}\text { C:18:1 ácido } \\
\text { oléico }\end{array}$ & $\begin{array}{c}\text { C:18:2 ácido } \\
\text { linoléico }\end{array}$ & $\begin{array}{c}\text { C: } 18: 3 \text { alfa- } \\
\text { ácido linolénico }\end{array}$ \\
\hline 4 & $10,40 \%$ & $80,03 \%$ & $4,87 \%$ & $0,42 \%$ \\
\hline 5 & $12,32 \%$ & $74,77 \%$ & $7,90 \%$ & $0,82 \%$ \\
\hline
\end{tabular}

$1=$ mistura de azeite de oliva virgem e óleo de soja, fabricação nacional;

$2=$ azeite de oliva virgem, com acidez máxima de $1 \%$, produzido e envasado em Portugual, importado por empresa Nacional;

$3=$ azeite de oliva extra virgem, com acidez máxima de $0,8 \%$ produzido e envasado no Uruguai, importado por empresa Nacional;

$4=$ azeite de oliva extra virgem, com acidez máxima $0,3 \%$ importado da Grécia;

$5=$ azeite de oliva extra virgem, com acidez máxima de $0,5 \%$, produzido na Itália e importado por uma empresa do Brasil.

Fonte: Lardini (2012).

Já a amostra 3 (azeite de oliva extra virgem), em comparação com as outras amostras está com uma concentração de ácido linoleico e palmítico maior, esses ácidos graxos se encontram em maiores concentrações em óleos. Mas como a legislação tem ampla faixa de concentração de ácido linoleico, palmítico e oleico a amostra está de acordo com a legislação, entretanto quando comparada a outra amostra de azeite de oliva nota-se a diferença na concentração do ácido oleico, característico do azeite de oliva. Essas características da amostra nos levam a perceber uma possível fraude por adição de óleo, pois a faixa de concentração dos ácidos graxos é ampla, possibilitando a adição de outros óleos para reduzir custos e aumentar lucros (LARDINI, 2012; BRASIL, 2012).

Conforme estudo de LARDINI (2012) a composição em ácidos graxos das amostras 2 (azeite de oliva virgem), 4 e 5 (azeite de oliva extra virgem), descritas na são características do azeite de oliva, pois o ácido oleico está em maior concentração e o ácido linoleico está em menor concentração, característico do azeite de oliva. Considerando BRASIL (2012), a concentração de ácidos graxos das amostras está de acordo.

Na análise de estatística (teste T), realizada nos principais ácidos graxos presentes no azeite de oliva, ácido oleico e ácido linoleico, verificou-se que as diferenças entre os teores de ácidos graxos nos lotes avaliados, estatisticamente não é significativa $(\mathrm{p}<0,05)$.

\section{CONCLUSÃO}

Através das análises físico-químicas realizadas, constatou-se que os quatro lotes avaliados encontram-se dentro dos parâmetros da legislação vigente, conforme Brasil (2012). Além disso, os resultados dos experimentos demostram que os azeites de oliva são de boa qualidade, foram adequadamente obtidos do fruto da oliveira unicamente por processos mecânicos ou outros meios físicos, com controle de temperatura, mantendo-se a natureza do azeite 
sem se levar a deterioração, embalados e estocados, protegidos da luz, do calor e da ação do oxigênio.

Na determinação da cor, os resultados obtidos mostraram que as amostras B e C apresentaram maior intensidade na coloração verde, e as amostras A e $\mathrm{D}$ apresentaram maior intensidade na coloração amarelo, as alterações de cor possivelmente estão relacionadas com a decomposição da clorofila no processo de fotoxidação e ou exposição à luz, devido ao armazenamento. Pode também existir relação da cor com o grau de amadurecimento, variedade e processo de elaboração do azeite (aquecimento controlado durante a centrifugação).

Os resultados das análises de acidez, índice de peróxido, coeficiente específico K232 e K270 obtidos, confirmaram as informações dos rótulos das amostras analisadas, onde se percebe que as empresas estão cada vez mais rigorosas nesses parâmetros de qualidade, pois o consumidor está cada dia mais informado e atento quando adquire o produto, buscando alimentos seguros e nutricionais.

Os valores da determinação de ácidos graxos mostraram que os azeites de oliva extra virgem avaliados, estão de acordo com a legislação vigente (Brasil, 2012). Que não sofreram nenhum tipo de adulteração, e sua composição em ácidos graxos mostrou que os azeites por possuírem mais de $80 \%$ do total, de ácidos graxos insaturados,

\section{REFERÊNCIAS}

AYTON, Jamie, MAILER, Rodney J. e GRAHAM, Kerrie. The Effect of Storage Conditions on Extra Virgin Olive Oil Quality. RIRDC Publication, 2012.

ALVES, Júnia de Oliveira et al. Espectrometria de Massas Com Ionização Electrospray (ESI-MS) e Métodos Quimiométricos: Caracterização de Azeites de Oliva (Extra Virgem e Puro) e Outros Óleos Vegetais e Quantificação de Óleos Adulterantes em Azeite de Oliva Extra Virgem. Belo Horizonte, 2010. Disponível em: $<$ www.bibliotecadigital.ufmg.br>. Acesso em: 14 mar. 2016.

AOAC Official Method. Fat (Total, Saturated and Unsaturated) in foods, hydrolytic extraction gas chromatographic method, revised 2014. In: Official Methods of Analysis of AOAC International, 128 th Edition.

ARAÚJO, Júlio M. A. Química de alimentos: teoria e prática. 4. ed. atual. ampl. Viçosa: UFV, 2009.

ARAÚJO, Wilma M. C.; MONTEBELLO, Nancy de Pilla; BOTELHO, Raquel B. A. (Orgs). Alquimia dos alimentos. 2. ed. Brasília (DF): SENAC-DF, 2008.

BOBBIO, Florinda O.; BOBBIO, Paulo A. Introdução a química de alimentos. 3. ed. São Paulo: Varela, 2003. 
BRASIL. Ministério da Agricultura, Pecuária e Abastecimento - MAPA. (2005), n. 1, de 30 de janeiro de (2012). Regulamento Técnico do Azeite de Oliva e do Óleo de Bagaço de Oliva. In: Diário Oficial da União, Brasília, 2012.

BRASIL. Ministério da Saúde. Agência Nacional de Vigilância Sanitária. Métodos físicos e químicos para análise de alimentos, 4. ed. Brasília, 2005.

CALDAS, L. B. S; MEDEIROS, R.M.L.; SANTOS, B.M.; Souza, F.C.; CELEDHINI, R.M.S. Análise dos compostos bioativos presentes no azeite de oliva extra virgem orgânico nacional. Unicamp, 2012.

CARDOSO, Luis G. V. Características físico-químicas e avaliação do perfil de ácidos graxos de azeites obtidos de diferentes variedades de oliveiras introduzidas em Minas Gerais - Brasil. Minas Gerais - Brasil, 2006.

CECCHI, H. M. Fundamentos teóricos e práticos em análises de alimentos. 2. ed. Campinas: Editora da Unicamp, 2003.

CODEX ALIMENTARIUS (FAO/WHO). Trade Standard Applying to Olive Oils and Olive Pomace Oil. Standard for olive oils and olive pomace oils. Codex Stan 33-1981. Roma, Itália, rev. 2, 2003.

COI. Intemational Olive Council. Disponível em: <http:/ /www.internationaloliveoil. org/>. Acesso em: 02 ago 2016.

COLLINS, G. L. B.; BONATO, P. S. Introdução a métodos cromatográficos. 7. ed. Campinas: UNICAMP, 2005.

COUTINHO, E.F.; RIBEIRO, F.C.; CAPPELLARO, T.H. Cultivo da Oliveira (Olea europea L.), Sistemas de Produção 16 [online], Embrapa. Pelotas, RS, 2009.

DAMODARAN, Srinivasan; PARKIN, Kirk L.; FENNEMA, Owen R. Química de alimentos de Fennema. 4. ed. Porto Alegre: Artmed, 2010.

DEON, Rúbia Garcia et al. Consumo de alimentos dos grupos que compõem a pirâmide alimentar americana por idosos brasileiros: uma revisão. Ciência \& Saúde, v. 8, n. 1, p. 26-34, jan./abr. 2015. Disponível em: <http://revistaseletronicas.pucrs.br/ ojs/index.php/faenfi/about/>. Acesso em: 05 mar. 2016.

European Union Commission. Regulation EEC 2568/91 on the characteristics of olive oil and olive-residue oil and on the relevant methods of analysis. Official Journal of European Communities, L248, 1991.

FORNAZARI, Maynara et al. Comparação dos valores do colesterol total, ldl colesterol e hdl colesterol com os valores da porcentagem de gordura corporal..

Revista da Faculdade de Ciências Médicas de Sorocaba, Sorocaba, v. 6, n. 1, p. 15 20, 2004.

Instituto Nacional de Metrologia, Qualidade e Tecnologia - INMETRO. Relatório de Análise de Azeite de Oliva Extra Virgem. dez., 2015. Disponível em: <http://www. 
inmetro.gov.br/consumidor/produtos/azeite-de-oliva-extravirgem.pdf $>$. Acesso em: 05 mar. 2016.

INTERNATIONAL ORGANIZATION FOR STANDARDIZATION - ISO. ISO

Method 12228:2014. Animal and Vegetable fats and oils- Determination of individual and total sterols contentes - Gas chromatographic method. International Organization for Standardization, [S.1.], 2014.

JORGE, Zaida Luiza Camacho et al. Análise Sensorial, Consumo e Qualidade de Azeites de Oliva Virgem Extra. Pelotas, 2013. Disponível em: <http:/ /www.dcta. create.inf.br/manager/uploads/documentos/teses/tese_sensorial_azeite_de_oliva. pdf>. Acesso em: 07 maio 2016.

LANÇAS, F. M. Cromatografia em fase gasosa. São Carlos: Acta, 1993.

LARDINI, Vanessa. Avaliação da estabilidade térmica do azeite de oliva e outros parâmetros físico-químicos. Passo Fundo, 2012.

MINOLTA. Precise color communications. Color Control from Feeling to Instrumentation. Osaka, Japan: 1994.

MODOLO, Juliana Stefanon. Quantificação de estigmatadienos em azeite de oliva (Olea europea L.) por cromatografia em fase gasosa. [S.1.], 2007. Disponível em: <http:/ / www.bibliotecadigital.unicamp.br/document/?code=vtls000415369>. Acesso em: 25 abr. 2016.

MORETTO, Eliane; FETT, Roseane. Tecnologia de óleos e gorduras vegetais nas indústrias de alimentos. São Paulo: Livraria Varela, 1998.

OETTERER, Marilia et al. Fundamentos de ciência e tecnologia de alimentos.

Barueri: Manole, 2006.

PENZ, L. R. Estudo das alterações físico-químicas do azeite de oliva após tratamento térmico. 2010. Dissertação (Mestrado) - Mestrado em Ambiente e Desenvolvimento, Centro Universitário UNIVATES, Lajeado, 2010.

PINHEIRO, Denise Maria; PORTO, Karla Rejane de Andrade; MENEZES, Maria Emília da Silva. A química dos alimentos: carboidratos, lipídios, proteínas e minerais. Conversando sobre ciências em Alagoas. Maceió: EDUFAL, 2005.

RODRIGUES, Ângelo M.; CORREIA, Carlos. Manual da Safra e Contra Safra do Olival. Instituto Politécnico de Bragança, 2009.

ZENEBON, Odair; PASCUET, Sadocco Neus; TIGLEA, Paulo (Coords.). Métodos físico-químicos para análise de alimentos. São Paulo: Instituto Adolfo Lutz, 2008.

ZILLER, Steve; FUENTE, Juan Luis de la. Grasas y aceites alimentarios. Saragoça: Acribia, 1996.

YILDIRIM, Gaye. EFFECT OF STORAGE TIME ON OLIVE OIL QUALITY. Turkei: Ízmir Institute of Technology, 2009. 